\title{
Interactive comment on "Sensitivity of atmospheric forcing on Northern Hemisphere ice sheets during the last glacial-interglacial cycle using output from PMIP3" by Lu Niu et al.
}

\section{Anonymous Referee \#2}

Received and published: 16 February 2018

Review of "Sensitivity of atmospheric forcing on Northern Hemisphere ice sheets during the last glacial-interglacial cycle using output from PMIP3" by Niu et al.

The study aims to investigate the role of atmospheric forcing on the Northern Hemisphere ice sheets evolution during the glacial cycle. The reports on a set of sensitivity experiments carried out with a continental ice sheet model. The climate forcing is is generated by linear interpolation between atmospheric fields representative for the LGM and the present day climate. LGM fields are taken from and earth system model that was applied for the LGM whereas present day climate is represented by an reanalysis product. The uncertainty of model results was estimated by repeating the 
experiments with a series of atmospheric forcing data sets provided by suite of PMIP3 model output. The response of continental ice sheets to climate change is an important topic in current climate research and is highly relevant for paleoclimatic questions addressing glacial interglacial climate cycles. While the results self are interesting I see a number of shortcomings and lack of information that prevent me from publication this study in CP in its present form.

\section{General Comments}

1) The present day climate is represented by a reanalysis product for the period 19812010. Why did you not take climate model output for the pre-industrial period? There are numerous preindustrial equilibrium outputs available from cmip3 and cmip5 models (which I think would be more consistent as also for the LGM a climate model output is used). A reanalysis product 1981-2010 contains the hottest years of the previous century and represent a climate that is already perturbed especially in high northern latitudes. This should be discussed somewhere. E.g how does this influence climate forcing you generate etc.. What is the effect on the obtained results?

2) Generation of forcing. a) Section 2.2 describes the generation of the forcing for the period LGM ( 21kyrBP) and PD (0 kyrBP). But section 4 starts with a discussion of modeled sea level equivalent time series that goes back to $120 \mathrm{kyBP}$. I tried to figure out how the forcing was generated before 21 kyBP but didn't succeed. Or did I oversee something? b) Furthermore, for those readers that are not so familiar with ice sheet modeling a bit more on the theoretical background would be good. It may be surprising that radiative heat fluxes are not explicitly given in the forcing. What is the reason for?

3) Discussion of results. The main conclusion supports previous evidence that summer temperature dominates the evolution of ice mass and its distribution. While this appears plausible already from a basic theoretical point of view a deeper discussion on the individual roles of temperature and precipitation (which solely represent the atmospheric forcing in this study) would be helpful. The role of precipitation during periods of ice 
accumulation is already mentioned. Here the study could really benefit from twin experiments in which on forcing (e.g. temperature) is kept fixed to LGM conditions whereas the other forcing (precipitation) follows the transient dynamics calculated as described in section 2.2. If this is reasonable given the available computational resources, this would help to really isolate individual effects of precipitation and temperature changes.

The study estimates a threshold value $\sim-5$ degree to foster ice accumulation. Is there evidence from real present day distribution and temperature records that support this. There are a lot of high quality reanalysis products available with sub daily output frequency that might be used to support the deduce relationship for at least the Asian glaciers. Or is there literature available to discuss this further?

4) No attempt has been undertaken to validate the model in the present day climate period. This would be helpful to get an impression of the validity of the model results for individual regions like Asia or Greenland.

5) Sensitivity experiments using PMIP3 model output. Here a discussion is provided about the effects of ablation due to warmer temperature and accumulation due to winter time precipitation. This could be deepened. Why accumulation dominant during winter in LGM. Geological evidence shows that larger ocean parts in the N-Hemisphere were ice covered during LGM compared to today which one might suppose to affect accumulation negatively while partly ice free condition during summer might foster ice accumulation? Here a discussion about available geological/paleoceanographic evidence would be useful. What is the known about the atmospheric moisture transports and sources during the LGM?

\section{Specific Comments}

Page 1 Titel. What is the message here? Do you aim to investigate the sensitivity to the ice sheet configuration or the other way round the sensitivity of ice sheets to the atmospheric forcing. I suggest to check the whole MS by a native English speaker.

\section{CPD}

Interactive

comment
Printer-friendly version

Discussion paper 
line 21 change climate system to climate sytem compartments. We probably have only climate system that can operate in obviously very different modes.

line 22 ocean circulation feedback. Be more precise. What is meant ? ocean heat transports? Vertical mixing dynamics?

Page 2 line 16. Missing processes are not only a problem in EMICS but in more complex earth sytem models as well. Often EMICS include even more processes the comment model of advanced complexity but are higher parameterized.

page 3 line 7: in section 2.2 so far I see only the production of forcing LGM -> PD is described. How is the forcing from 122.9 -> LGM produced Or do I miss something? Please give a reference or discuss the choice of present day condition for the ice sheet model initialization. Ice sheets have perhaps the longest memory in the climate system and thus will probably never reach equilibrium with any kind of external forcing (especially not the fast atmosphere). In turn one would assume initial condition have particular importance.

page 5 line 3-4. How is this white noise generated and is that step really necessary? As i understood you form a glacial index from NGRIP (section 2.2) which is smoothed by 50 year averages.

line 12ff. why not use GCM output for the preindustrial period instead of using a reanalysis product which would be physically more consistent.

page 7 line 14: Ok but the Rohling sea level reconstruction was also used to force the model, well? Figure 5 show also interesting mismatches between the curves. E.g at arounf 65 kyp present we see opposing trend in sea level. It seems that the Rohling curve sometimes leads the modeled curve. Could that be caused by a mismatch of age model between NGRIP isotope curve (which is tuned orbitally, I would guess?) and the the Rohling sea level curve?

line 27: Section 4.1.1 is rather descriptive as a whole. It is clear that D-O cycles 
arise from the NGRIP forcing. Is it possible further elaborate which regions are mainly contributing to these variations. Figure 5 distinguishes only Eurasia, North America, and Greenland. It could be worth to identify the key regions that most respond to D-O cycles and discuss this with available literature.

Interactive comment on Clim. Past Discuss., https://doi.org/10.5194/cp-2017-105, 2017.

CPD

Interactive comment 